The University of Maine

\title{
DigitalCommons@UMaine
}

Sociology School Faculty Scholarship

Sociology

2-2009

\section{Doing Good, Being Good, and the Social Construction of Compassion}

Amy Blackstone

University of Maine - Main, amy.blackstone@umit.maine.edu

Follow this and additional works at: https://digitalcommons.library.umaine.edu/soc_facpub

Part of the Civic and Community Engagement Commons, Gender and Sexuality Commons, $\underline{\text { Politics and Social Change Commons, and the Social Psychology and Interaction Commons }}$

\section{Repository Citation}

Blackstone, Amy. 2009. "Doing Good, Being Good, and the Social Construction of Compassion." Journal of Contemporary Ethnography, February 2009; vol. 38, 1: pp. 85-116. DOI: 10.1177/0891241607310864

This Article is brought to you for free and open access by DigitalCommons@UMaine. It has been accepted for inclusion in Sociology School Faculty Scholarship by an authorized administrator of DigitalCommons@UMaine. For more information, please contact um.library.technical.services@maine.edu. 


\title{
Doing Good, Being Good, and the Social Construction of Compassion
}

\author{
Amy Blackstone \\ University of Maine
}

\begin{abstract}
Activists and volunteers in the United States face the dilemma of having to negotiate the ideals of American individualism with their own acts of compassion. In this article, I consider how activists and volunteers socially construct compassion. Data from ethnographic research in the breast cancer and antirape movements are analyzed. The processes through which compassion is constructed are revealed in participants' actions and in their identities. It is through their actions (or "doing good") and their perceptions and presentations of themselves ("being good") that participants construct compassion as a gendered phenomenon. Together, the processes of doing good and being good raise questions about the extent to which participants' acts of compassion are or can be transformative in a way that promotes the social change which activists and volunteers seek.
\end{abstract}

Keywords: civic engagement; activism; gender; ethnography

$\mathrm{H}$ ow do social movement participants ascribe meaning to what they do, and what do these representations mean for our understanding of compassion more generally? In this article, I analyze the processes whereby activists in two social movement organizations attach gendered meanings to their efforts. Specifically, I consider activists' "acts of compassion" (Wuthnow 1991) in the breast cancer awareness and campus antirape movements. Bridging the civic engagement and social movements literatures, this research contributes to both by revealing how activists' acts of compassion are gendered. From theoretical accounts which examine civic participation in

\footnotetext{
Author's Note: Thank you to Ron Aminzade, Lara Cleveland, Alyssa Goolsby, Doug Hartmann, and Amy Ronnkvist for their comments and support during various stages of this work and to Alyssa Radmore for research assistance. And an especially heartfelt thanks to the activists and volunteers described in this article for all of the good that they do and for allowing me to be a part of it. This research was supported by a dissertation improvement grant from the University of Minnesota's Department of Sociology.
} 
the United States and liberalism more generally (e.g., Berlin 1984; MacIntyre 1984; Rawls 1984) to empirical examinations of such (e.g., Bellah et al. 1985, 1991; Wuthnow 1991), gender has rarely been included as an analytic concept that shapes and informs the ways that individuals participate in civic life. While the social movements literature has certainly established that gender matters for participation (e.g., Adams 2002; Ferree and Martin 1995; McAdam 1992; and Taylor 1996), the civic engagement literature highlights the relevance of our individualist culture to the gendered processes of movement participation. Drawing from both of these literatures, I show how the processes of "doing good" and "being good" operate in two diverse social movements. Together these literatures frame my own study of the relevance of individualism and gender for how activists conduct and construct their acts of compassion.

Though similar in the sense that both the breast cancer and antirape movements have something to do with gender, these movements also contain important differences that make their comparison useful. While antirape activism has its roots in the second-wave feminist movement of the 1970s (Bevacqua 2000; Brownmiller 1975; Odem and Clay-Warner 1998), breast cancer activism grew out of the subsequent "backlash" (Faludi 1991) period of the 1980s (Blackstone 2003; King 2006; Klawiter 1999; Taylor and VanWilligan 1996). ${ }^{1}$ Their different historical origins might lead one to conclude that that each movement would take a radically different approach toward gender relations. While this is true in some respects, results from my ethnographic research show that in conducting the day-to-day work of the movement, the gendered processes by which participants construct compassion are similar. Those processes are represented by participants' actions, or how they actually go about doing the work of their movement, and by their identities, or how they perceive and present themselves.

Throughout the article, I refer to participants' actions as "doing good" and their perceptions and presentations of themselves as "being good." Doing good and being good are both social processes that participants engage in as they go about conducting the work of their movement. By analyzing these processes, we can see how activists and volunteers construct compassion in a way that is gendered, raced, and classed. While all three dimensions of compassion are important, the data presented here were collected with gender as the central point of focus. Therefore in this article, I primarily address how compassion is gendered. ${ }^{2}$ In particular, I examine how activists and volunteers deal with the social consequences of gender essentialism and what their approach means for the changes that they seek. For both the breast cancer and antirape movements, the culturally predominant ideology of gender essentialism shapes what they do and how they do it. 
Gender essentialism has had negative repercussions for both movements. Of particular relevance to the breast cancer movement, traditional views of gender contributed to the creation of the predominant medical model in which women patients are too-often constructed as crazy or bothersome and in which their concerns are not taken seriously by their doctors (e.g., Lorber 1997). This model disempowers and silences women. In the case of the antirape movement, gender essentialism helps create a culture in which women are not only the most likely victims of violence but also disempowered and limited as a result of being conceived only as victim (or potential victim) rather than as fully competent. Men are also negatively impacted by gender essentialism as this ideology boxes them in as either predators or protectors of women as opposed to being viewed as women's partners in the fight against violence and gender inequality.

In sum, the very problems that both movements fight against are, at least in part, borne out of gender essentialism. But while essentialist constructions of gender may be to blame for the social problems of a flawed medical system and sexual violence, participants themselves do not necessarily make this connection. Thus a compelling paradox, and the crux of my analysis, results: while participants work to undo the consequences of essentialist gender constructions (whether consciously or not), their actions and identities sometimes reify traditional visions of gender. In the following pages, I describe these findings in more detail. First I place my work within the context of prior scholarship on the social construction of compassion and set the stage for my own analysis by describing my research sites and methodological approach. While most my prior work on this project has been anchored in the social movements literature (Blackstone 2003, 2004, 2007), here I start from the literature on civic engagement. I aim to bridge these two related but distinct literatures by considering how what we know about the roles of gender and emotions in social movements informs the processes through which activists and volunteers construct compassion.

\section{Literature Review}

More than one hundred years ago, Tocqueville ([1835] 1966) observed a seeming contradiction in American life: that Americans are simultaneously compassionate, civic-minded volunteers and rugged, do-it-yourselfer individualists. That our acts of compassion and ideas about doing good are enmeshed with American ideals of individualism comes as little surprise considering the long history of social scientific research documenting this relationship. Tocqueville's observation is echoed in the work of several 
scholars including Bellah (1985) and colleagues $(1985,1991)$ and Wuthnow (1991). In their work on the relationships between individualism and commitment, Bellah and colleagues $(1985,1991)$ demonstrate that the dominant American ideology of individuals pitted against institutions (as opposed to working in concert with them) shapes how we deal with social problems. More recent research highlights the dilemmas experienced by women and men who find themselves faced with contradictory social changes which position both self-interest and care for others as obligatory but incompatible (Gerson 2002).

These findings might lead one to question Americans' compassion for others or, at the very least, their capacity to work toward institutionallyoriented social change. Such conclusions, however, would overlook the complexities of doing good. As Lichterman (1996) argues, the emphasis on self-interest in the United States is not necessarily incompatible with commitment to institutionally oriented change. Instead, individuals seeking selffulfillment often do so within a community of others and through communal ties and interactions. It is through these interactions, in which individuals pursue self-fulfillment at the same time that they connect with others, that we can observe movement participants constructing compassion. Breast cancer and antirape activism are particularly useful sites for such observations-in both cases, participants' involvement is often inspired by personal experience and desire for empowerment at the same time that participants seek connections to others and future change. Perhaps the relationship between individualism and compassion is complex but, as the activists I studied demonstrate, the two are not necessarily incompatible.

One consequence of the dominant individualist perspective in the United States is that those who "do good" may fail to connect their own good works to the broader social context within which they occur. That context is one in which a complex set of power relations including those related to issues of race, social class, and gender shape not only the social problems being addressed by activists but also the actions taken to confront those problems. Indeed, acts of doing good have been shown to be "heavily tinged with class, ethnic, and racial concerns" (McCarthy 1990, x), and this has been documented by many scholars (e.g., Bellah et al. 1985, 1991; Coontz 1992; Evans 1997; McCarthy 1990; Mink 1990; Naples 1992, 1998; Ryan 1992; Wuthnow 1991). For example, Evans (1997) notes that the "female values" espoused by early women reformers at the turn of the last century in fact "represented the politicized domesticity of middle-class women with its associated prejudices towards blacks, immigrants, and the working class" (p. 172). Research on more contemporary periods shows that doing good 
continues to be complicated by issues of power and inequality (e.g., Blackstone 2003) and even by issues of geography (Petrzelka and Mannon 2006).

In addition to its race and class dimensions, doing good is also gendered. Yet prior research examining acts of compassion does not consider the gendered nature of doing good as thoroughly as it could. The social construction of compassion is implicitly linked to the social construction of gender. While doing good is clearly not limited to those of particular race or class identities, stereotypes about gender can lead one to take women's acts of compassion for granted (Blackstone 2004; Daniels 1985 and 1988; DeVault 1991; Hays 1996). Because women are stereotypically thought of as natural caretakers, nurturers, or mothers (and may even view themselves in this way [Gerstel 2000]), their acts of compassion may be viewed as unexceptional and therefore unworthy of attention. Men who do good, on the other hand, may be constructed as nonconforming individualist heroes. While interviewing Americans about their own acts of compassion, Wuthnow (1991) discovered that many volunteers present themselves as "rugged individualists" whose stories conjure up images of American heroes from Abraham Lincoln to Davy Crockett, men who represent American ideals of nonconformity, freedom, and hard work. These heroes expressed compassion in a way that also emphasized their masculine character, and their identities as individuals. The gendered nature of these images tends to be overlooked in the civic engagement literature, however. To understand where and how gender fits into "acts of compassion," I next draw from the social-movements literature, which has more thoroughly considered the role of gender and emotion in shaping participation.

As with many of the scholars discussed thus far, whose work focuses on tensions between individualism and compassion, a number of socialmovements scholars have considered similar tensions. In particular, the shift to what movements scholars refer to as "new social movements" resulted in increasing attention to the tension between individually oriented change and institutionally oriented change (see Giddens 1979). Theories of new social movements grew out of a critique of earlier resource mobilization and political process models, which some said could "not explain how structural inequality gets translated into subjectively experienced discontent" (Taylor and Whittier 1992, 104). New social movements have been characterized by their tendency to focus on collective identity and issues of day-to-day life. Additionally, the work of these scholars on the role of emotion in social movements is helpful for understanding the processes of doing good and being good (see, e.g., Flam and King 2005; Goodwin, Jasper, and Polletta 2001; Jasper 1998). 
While the social-movements literature traditionally focused on groups seeking institutional change, scholars of new social movements, including Taylor (1996), argue that groups seeking personal change can also be considered a social movement. Participants in women's self-help groups such as postpartum depression groups (in the case of Taylor's work) or groups for survivors of breast cancer or rape, for example, might be conceived as activists who work to rewrite "feminist concerns in the language of everyday women" (Taylor 1996, dust jacket). By identifying their common interests, these movement participants are able to bridge the gap between their personal troubles and public issues by interpreting their problems in collective terms. Such groups often help to "normalize experiences traditionally regarded as deviant" (Taylor and Van Willigen 1996, 128). Constructing survivors' identities as nondeviant is an important aspect of both the breast cancer and antirape movements. Such identity construction is "an essential component in collective action" and identity "develops and is renegotiated via various processes" within movements (della Porta and Diani 1999, 109). Participants in my study construct their identities through the processes that I refer to as doing good and being good.

By conceiving of their experiences in and on their own terms and presenting their conceptions of self publicly, participants in the breast cancer and antirape movements engage in the process I refer to as being good. And because they do this not only for themselves but with the intention to create some form of collective change, they also engage in the process of doing good. Of course, both of these processes occur within the contemporary social context, which means that both processes are gendered. Research by scholars who have studied the role of gender in social movements is particularly instructive for considering the ways that compassion is gendered (see, e.g., Adams 2002; Ferree and Martin 1995; McAdam 1992; and Taylor 1996). Work by scholars who have challenged the conceptual distinction between charity work and activism is also helpful (Beisel 1997; Clemens1997; Ginsburg 1989; McCarthy 1990; Naples 1998; Pardo 1995; Reagan 1997; Taylor 1996). These scholars have sought to overcome the tendency to overlook certain forms of women's activism. Some of the main contributions of these works include explication of the gendered nature of politics and political participation, rich descriptions of middle-class women's activism and charity work, and the placement of women's activism within the larger historical context of women's charity work. Middle-class women in particular occupy the unique position of benefiting from certain aspects of "the way things are" at the same time that they have a stake in changing aspects of social structure, culture, and politics. Works by Beisel (1997), 
Ginsburg (1989), and Taylor (1996) are especially instructive in demonstrating this point. By showing that women's activist/charity work in relatively private arenas indeed has public implications and repercussions, these authors urge us to stretch our consideration of what it means to be compassionate, to do good, and to be good.

An analysis of activists' acts of compassion reveals two points that contribute to existing social movements theory: first, that participation in movements is contradictory and second, that these contradictions have unintended consequences for whole groups based on social categories. As theories of social movements have shifted from focusing on breakdowns, to resources, to political processes, and finally to identities, the role of contradictions in participants' lives, stories, emotions, and actions in shaping social change has not been considered to the extent that it could be included. This is significant for several reasons. First, that the emotional work centered on doing and being good is contradictory is important because emotions are linked to morality (Jasper 1998). If only particularly gendered, raced, or classed individuals are constructed as those who do good, it is possible that those who are left out will be constructed as less good, perhaps less moral. Even work which emphasizes the importance of understanding the context within which activists operate (e.g., Klawiter 1999; Ray 1999) sometimes presumes consistency within particular contexts despite attention to inconsistencies across contexts. Yet analysis of activism in the breast cancer and antirape movements shows that contradictions exist even within single movement organizations, fields of protest (Ray 1999), and cultures of action (Klawiter 1999). These contradictions are important for understanding the processes of doing good and being good.

Considered together, the civic-engagement and social-movements literatures provide new insights about how compassion works. From the civicengagement literature, we know that ideals of individualism shape how members of society conceive of themselves and their good works. From the social-movements literature, we know that in addition to the broader cultural context of individualism, emotions matter for how movement participants do their work and think of their efforts. Indeed, as Flam and King (2005) suggest, "emotions connect the macro-politics to the micro-politics of social movements" (p. 3). In a call to researchers to further examine the role of emotion in social movements, Polletta and Amenta (2001) suggest that scholars should consider the dominant cultural context (in this case, individualism) and how it shapes "widespread perceptions of what is strategic, what is political, what is an interest, and what is good" (p. 316). I aim to do just that by considering how the dominant culture of individualism 
shapes what activists view as good. Importantly, as several movements scholars demonstrate, the processes by which "good" is constructed are gendered-how activists and volunteers $d o$ good is gendered and how they are good is gendered. These insights provide the framework for my own analysis of the ways that compassion is both gendered and tied to individualist ideals. Following a discussion of my research sites and methodology, I analyze the processes by which participants do good, how they conceive of themselves and their good works (how they "are good"), and how gender is salient throughout those processes.

\section{Data and Method}

My analysis is based on ethnographic research in two social movements. The bulk of my data come from my participation in two organizations but I also attended other movement-related events and conferences during my years of participation. I began the study with a focus on the case of breast cancer activism but later added that of sexual-violence awareness to compare similarities and differences across the two cases. Adding the second case enabled me to better illustrate common patterns among the cases (Burawoy 1981, 98) and among activists' efforts more generally. I therefore compare the case of breast cancer activism to that of the sexual-violence awareness movement. My study includes over three hundred hours of participant observation over a period of three and a half years (from January 1999 to June 2002) and data from ten formal and over fifty informal interviews with social-movement participants.

My primary research site was a state affiliate of the Susan G. Komen Breast Cancer Foundation, where I conducted field research by participating as a member of the local steering committee, assisting the volunteer staff at Komen's Race for the Cure office, and volunteering at a variety of fundraising events. I compare data collected through my participation at Komen to data collected from participation at a campus antirape organization in the Midwestern United States, referred to here as Stop Rape. I participated at Stop Rape for about a year, during which time I attended two intensive forty-two-hour training sessions and retreats and "hung out" in the Stop Rape office assisting staff and other volunteers with the day-to-day management of the office and observing everyday goings-on. I also analyze data that I collected from participation at a national sexual-violence advocacy conference put on for those involved in the campus antirape movement, a national breast cancer advocacy conference, and an international 
conference on breast cancer. This case-oriented qualitative approach (Ragin 1987) helps situate me to discover the effects of various combinations of conditions including the temporal origins of the movements, their organizations, and individual movement participation as well as the movements' varying cultural and spatial contexts.

The Komen Foundation and Stop Rape are useful cases from which to examine activists' constructions of doing good. Though I cannot speak to the broad generality of the processes observed in this qualitative case study, having two cases to compare does enable me to consider patterns that might not otherwise be evident in a single case study. The two particular organizations where I participated contain interesting similarities at the same time that they maintain important differences. The Komen Foundation was founded in 1982 (Brinker and Harris 1995), just when the breast cancer movement began to take shape and within the context of an increasingly powerful antifeminist backlash. Stop Rape, on the other hand, traces its origins to earlier antirape work during the second-wave feminist movement of the 1960s and 70s. Despite these differences, both organizations are engaged in social change efforts and, based on my interviews with participants, both organizations implicitly include empowering women as part of their mission. ${ }^{3}$ Participants themselves also share interesting differences and similarities. While most of the participants in both organizations are white women with relatively privileged class backgrounds (though the class backgrounds of the Komen participants are slightly higher), they represent different life course stages and generations. Most of the breast cancer activists I studied were in their late thirties to early sixties while the sexual-violence participants tended to be in their late teens and early to mid-twenties.

This is an ethnographic study of activists' constructions doing good. My methodological strategy might, in at least some ways, be described as critical ethnography (Thomas 1993). I use the data provided by several years of participation, observation, and interviewing in multiple movements and sites to critique not only the social processes observed but also the theoretical concepts (e.g., activism, compassion, gender, and politics) around which those processes are centered. Some of my findings were surprising. For example, early on in the project I expected that the antirape activists I studied would be far more openly critical of gender essentialism than the breast cancer participants. To my surprise, each group of activist/volunteers in fact reinforced some aspects of the gender system at the same time that they, often only subtly, seemed to be critiquing aspects of it. Critical ethnography enabled me not only to confront the sometimes unexpected realities of my data but also to consider its subtleties. I attempt to analyze 
individual acts of compassion while also considering the broader contexts within which participants operate. At the same time that I intend to situate individuals, my methodological approach allows me to make a theoretical contribution by identifying anomalies and silences within social constructions of concepts such as compassion and good.

Unlike a grounded theory approach in which the aim is to discover new socially relevant theories (Charmaz 2005; Glaser and Strauss 1967), my intent is to offer an analysis of social processes and provide a framework for understanding how those processes inform existing scholarly knowledge. In the case of my own research, my participation at the Komen Foundation led me to discover anomalies in existing understandings of doing good at the same time that it highlighted silences in earlier scholarly discussions of doing good. Following the discovery of these silences, I attempted to verify my analysis by comparing findings from additional research sites including Stop Rape and the three movement conferences.

My analysis is based on data collected during my participation in both movements and drawn from field notes and formal and informal interview data. The formal interviews took place with three key informants at Komen and seven key informants at Stop Rape. These interviews lasted between sixty and ninety minutes each. I began each interview with an idea about the kinds of information I expected to gather and, with the formal interviews, used an interview guide outlining the key ideas I wished to discuss. I also urged participants to tell me about the experiences they felt were most important to share based on their knowledge of my interest in how they became active in the organization, how they conceive of their efforts (e.g., as activism, volunteerism, political, feminist, etc.), and what they view as the goals of their organization.

The informal interviews took place at the conferences I attended and at events held by Komen and Stop Rape. Sometimes referred to as "casual interviewing" (Lofland and Lofland 1995, 18), these interviews were less structured than the formal interviews and were not tape recorded. Most typically, the informal interviews occurred during "down times" at the conferences and events. In these moments, I would introduce myself to other participants, talk with them about my research, and ask them about their own participation. While I did not have an interview guide with me during these interactions, I considered an informal interview to have occurred at times when I guided the conversation with the intention to elicit specific information about a person's participation in the movement. In each of these instances, participants knew that I was both a participant and a researcher and that I was attending the event in both capacities. 
The bulk of my data are contained in the fieldnotes I took during my three and a half years of participation. I maintained my field notes by handwriting brief observations during training sessions, meetings, and events. Immediately following these events, I would transcribe the handwritten notes into a word processing program, elaborating them by including all information that I recalled but was unable to write out by hand. In addition, the typed notes include reflections on and analyses of the observations that I recorded (see Lofland and Lofland 1995). Informal interview data were recorded in my field notes while formal interviews were tape recorded and then later transcribed. I use pseudonyms for participants and, in some cases, have changed other minor but potentially identifying details about them.

\section{Constructing Compassion}

In this section, I consider how activists and volunteers in the breast cancer and antirape movements socially construct compassion. The processes through which compassion is constructed are revealed in participants' actions and in their identities. It is through their actions (or "doing good") and their perceptions and presentations of themselves (or "being good") that participants construct compassion as a gendered phenomenon. For example, participants would often essentialize gender differences at the same time that they worked to undo the social consequences of essentialist constructions of gender. Even if they did not directly challenge gender essentialism, many of their actions focused on resisting its consequencesat Komen, this meant empowering women to advocate for themselves as a form of resistance against women's poor treatment within the dominant medical model, while at Stop Rape this meant empowering women and men to work together in creating a nonviolent community. Participants also seemed to equate doing good with being good. Through their actions and presentations of themselves, participants expressed their views of what it means to be a "good" survivor, a good movement participant, and a good community member. Together, the processes of doing good and being good raise questions about the extent to which participants' acts of compassion are or can be transformative in a way that promotes the social change which activists and volunteers seek.

\section{Doing Good}

Participants' actions together with their own descriptions of their efforts reveal how doing good is gendered and also linked to class and race. In a 
previous publication on the gendered nature of activism at Komen, I describe how one participant referred to her activism as "just a bunch of us girls out there having a good time" (Blackstone 2004). Many times women participants in both organizations described their efforts as simply "having fun" or "hanging out" rather than as work or as activism. By framing what they do in this way, the effort women participants exert as they do good becomes less visible than it might be otherwise. In addition, participants construct men's and women's participation differently. While men participants tended to be constructed as heroes or protectors, women's identities as "victims" or as nurturers were emphasized.

In terms of the invisible labor conducted by women in the organizations, participants' actions around food were particularly telling. Food was present at nearly every Komen and Stop Rape meeting I attended. At Stop Rape, though men and women advocates both attended the meetings, I only ever observed the women participants pitch in to set up and serve the food during meetings. Admittedly, I contributed to this pattern-whenever there was food to be served at a meeting, I jumped up to help out along with the other women in the group but did not attempt to recruit any of men who were present to help out. It was only on reading my fieldnotes later on that this pattern became visible to me. Having only noticed this pattern on deliberate and extended reflection, I could not help but wonder how many other instances of women participants doing invisible care work I may have overlooked during my participation.

Komen participants also engage in labor that sometimes goes unnoticed. One way that Polly and Jane, two Komen participants who volunteer for the organization full-time and are both supported financially by husbands who work for pay, do this is by purchasing lunch for other volunteers on busy days in the Race for the Cure office. Doing so not only took financial resources but also required time and effort to order, pick up, and deliver the lunches. Usually the lunches appeared without mention of Polly and Jane's work to get them there. Not only was their work invisible, like much of the care work conducted by women, but a comment I overheard Polly make one day also got me thinking about how the food served highlights connections between social class and doing good. One day after bringing in lunch, I overheard Polly talking with Jane about what a good deal she got for the salads she had purchased for the group- "only $\$ 7.00$ each" for the ten or so volunteers working that day. That a $\$ 70.00$ lunch was perceived as a deal reveals the class status of these participants.

What Komen participants do not eat also tells us something about class, and possibly gender. For example, one local sponsor, the Dairy Queen, 
regularly provided snacks for the monthly meetings I attended. Every month a cooler full of cheap, high fat Dilly Bars and ice cream sandwiches would appear at the beginning of the meeting, get passed around, and get taken away at the end of the meeting just as stocked as when it arrived. Though the salads, carrot sticks, and soy lattes offered up at the Race office regularly got consumed, the Dairy Queen cooler arrived at and left every meeting completely full. Perhaps the avoidance of the Dilly Bars can most readily be viewed as connected to issues of body image and gender. But some scholars have suggested that food choices (or maybe better put-food options) are also connected to social class. For example, Calnan and Cant (1990) found that middle-class women tended to cite health concerns as a major influence on their food choices while working-class women did not cite health as a major influential factor. One explanation for this might be that those in the middle and upper classes have the luxury to make their food choices based on factors other than, or in addition to, food cost.

Just as women's participation is gendered in the food examples above, a look at how men's participation is constructed also reveals that participants "do gender" (West and Zimmerman 1987) as they go about doing good. Participants' actions in both movements seemed to imply that women are by nature more nurturing than men. Therefore, men who managed to overcome their (socially constructed) identities as hardened and noncaring by helping out in the movements were often held up as special heroes. When I began my participation at Komen, for example, I asked Polly if everyone who works for Komen is a volunteer. She said yes and went on to say, "And what's so neat about it is that lots of them aren't even breast cancer survivors. They just care. We even have a couple of men." Polly would not have said "We even have a couple of women" because she assumes that women are the ones who will do the work of the movement. When men pitch in, it is a special occasion.

The special occasion status afforded men's participation became clear the day my husband came with me to volunteer at a Komen event. Though women volunteer for Komen everyday, Lance received more kudos for his one day of participation than I had for the three months I had already put in by the time he came to volunteer. The following excerpt from my field notes describes my and Lance's arrival to volunteer at the Stomp It Out Snowshoe Festival:

We arrived at the volunteer tent and found Carla to get checked in. She said she was glad to see I came, and was especially impressed that my husband (or "hubby", as she said) was there to volunteer too. Nina was there 
and greeted us as well. She gave Lance a pat on the back and, beaming at him, said "Isn't it sweet that he came to help us girls out?"

Though it was no surprise that I, as just one of the girls, was there to help at the event, Lance's participation was interpreted differently. By not conforming to the way that other men at Komen participate (mostly by providing the financial resources that enable their wives to go about the work of doing good), Lance got to be the hero that day. As a woman, my own involvement was far less extraordinary.

The campus antirape movement also has its masculine heroes. At the sexual assault conference I attended I met four men who walked across the country in an event they named the Walk Across America, from San Francisco to Washington, D.C., over five months to raise awareness about sexual violence. That these men were to be the "heroes" of the conference became clear at the first evening's roundtable event and throughout the rest of week as I overheard a number of casual conversations about the four men and listened as their "amazing" walk came up in many subsequent panel presentations and sessions. That first evening, there were about twenty tables set up in one room, each with a sign posting the topics for that particular table. The Walk Across America men occupied one of those tables, designated as the table where we could hear about their adventures. Though their table was clearly the most packed at the beginning of the roundtable event, the other tables were also populated (if sparsely). But by the end of the evening participants from every table, including the one at which I had initially placed myself, had moved over to the Walk Across America table. As one of the participants at the table where I initially sat put it, "Something pretty good must be happening over there. We might as well see what it's all about." Therefore I, along my three other tablemates and the rest of the room slowly gravitated toward the four men. It was not until later writing up my fieldnotes and reflecting on the evening's events that it occurred to me that we had allowed these four voices to represent all of the topics we set out to discuss that night.

The four walkers sat around their table with a few others while the rest of us crowded around, forming a massive circle around them. The conversation was reminiscent of movies in which cowboys sit around the campfire and swap stores. Those of us encircling the table mostly stood in awe as we listened to the walkers' stories about why they did the walk and the adventures they had had while on the road. The four men described how they carried backpacks, sleeping bags, and a tent on their walk. When evening came they usually knocked on someone's door in whatever town they happened to be walking through and asked the resident if they could 
camp on the lawn for the night. Several times they were given a bed for the night or invited into someone's home to use the shower or the telephone. All of the men had explanations like the following, excerpted from one of the walker's personal stories, for why they did the walk:

I refuse to believe that all men are rapists, and I'm sick of men standing by while things go badly. Anything that I can do to make the world safer for my friends and family is not too much to do. (One in Four n.d.)

The walkers' explanations for conducting the walk represent them as hardy heroes and as protectors, walking to save their friends and family from the evil of sexual violence. Thus even in their explanations for their involvement, the walkers are doing gender as they do good: walking to protect "MY friends and family" (emphasis added) is protective but not nurturing of the world or of the community in the way that women's participation is expected to be. Furthermore, those of us who sat around the "camp fire" that night aided in the gendered construction of these masculine heroes by urging them to tell their war stories and praising them for, as one person in the audience put it, "doing so much for so many."

In addition to analyzing how the walkers represented their efforts and how those of us in the audience responded to them, it is also essential to point out that such activities could likely only have been done by four young men. Though the men said they feared for their safety once or twice during their five-month walk, safety would likely have been quite a different issue had the four walkers been college-aged women. When I asked these men and their fellow women activist students about this during a meeting with their campus antiviolence student group later on during the conference, they all agreed that women could not carry on such activities on their own-only men, they said, could have pulled off the Walk Across America event. Though it did not come up in our discussion, it is also relevant that all four men are white. Surely four nonwhite men would not have been as well received by the strangers on whose doors the men knocked each night when looking for a place to set up their tents. These men epitomize the rugged individualist ideal at the same time that they demonstrate their ability to "overcome" the normative construction of men as non-caring. Thus their actions present these men as tough, rugged individuals, and protectors of women, but they also enable the men to achieve the American ideal of nonconformity by revealing themselves as men who care.

Like the Walk Across America, opportunities specific to men exist at Komen as well, and the need for gender-differentiated participation is more 
often constructed by participants than by the existence of structural genderbased inequalities. While I was at Komen, a new group called Men for the Cure was created. The group was formed by two women members of the steering committee with the goal of creating activities to raise funds for and awareness about breast cancer in which men would feel comfortable participating. During one report to the steering committee, the Men for the Cure coordinators mentioned several times that it is important with Men for the Cure to find things for them to do that are not too "touchy feely." They said men would not want to be involved in events "like that." In an attempt to come up with an annual, ongoing opportunity for men to show their support for the cause, the coordinators considered such annual events as a tennis tournament and a bike race. Eventually they scratched both of these ideas in favor of creating a local garden that men were to be responsible for implementing and maintaining. No one mentioned that the coordinators chose a focus arguably more "touchy feely" than the physically challenging activities of tennis and biking.

Men's participation was also treated differently than women's by advocates at Stop Rape. When explaining why she believes there are so few men participants in the movement, Kate said the following during my interview with her:

Maybe it's more like men would be out there if there was a program that was going to, like, beat the crap out of offenders, maybe then there'd be more men than women.

Though none of the other Stop Rape advocates I spoke with suggested that men might be more interested in participating if they were allowed to "beat the crap out of offenders," all of the advocates were aware that most participants are women. Several participants echoed the sentiments expressed by Teresa during my interview with her. Teresa suggested that to get more men to participate, "we [Stop Rape participants] need to change male-female interaction in a way so that it is not so antagonistic." Similarly, Irene made the point that, "Some men are very uncomfortable being in an atmosphere where often men are the bad guys."

Flirting with men seems to be one way that movement participants try to show men that they are not always thought of as "the bad guys." Teresa said she was both surprised and embarrassed by her own flirtatious behavior while sitting at a Stop Rape information booth during a campuswide activities fair. Teresa recalled the experience when I asked her about how to get men involved. She said she did so by encouraging men to check out the Stop Rape information table. Teresa said, 
Oh yeah, I was saying, "Come get a pen, hurry, you cute one!” [Laughter] You know, bringing the men. And the sad thing is I never flirt except at this kind of thing. I was like all, "La, la, la, here's a pen, hi.” [Laughter]

When I asked if flirting was a conscious decision, Teresa said, "Oh yeah. Yeah, because it made it easier, especially for the men so that it wasn't [pounding on the table, in a stern voice] 'Come over here and get your pen!'”

Heterosexual bantering also went on at Komen. The following interaction occurred after a man doctor gave a guest talk at a monthly meeting and is an excerpt from my field notes:

At the end of his presentation Dee raised her hand and asked, "Can I have your phone number?" The doctor looked a little surprised and he mumbled something that I couldn't hear but it made a bunch of women laugh. Dee said, "No, I mean to contact you in case I have any follow-up questions. I'm the representative from [Komen's local television sponsor]." The doctor said in a joking way, "No. I'm happily married."

Although it may not be explicitly intended, heterosexual flirting at both organizations has the consequence of reifying heteronormative gender arrangements. It is important to note that this reification runs counter to the goals of the breast cancer and antirape movements which ultimately, if not always blatantly, seek gender equality within our social institutions and culture. While participants' descriptions and my own observations of heterosexual flirting at both organizations do not reveal any obvious negative consequences, such interactions may have the consequence of silencing expressions of gender that are not heteronormative. In this way, even through seemingly innocuous flirting, participants do gender as they do good.

In the end, Teresa at Stop Rape says it "doesn't matter" how we treat men's participation. She suggests that men really will not want to participate no matter what may be done to encourage it. Teresa did not express this opinion in a doom-and-gloom manner. She says she is content with the knowledge that women do, and will continue to do, the majority of work in the movement. The same seems to be true for the women at Komen. It's not that men are not welcome to participate. Rather, as the reaction to my husband's participation at the Snowshoe Festival demonstrates, Komen participants seem to wonder why men would want to participate. Men who do so, however, are extra special, even when their participation involves doing all the things that women in the organization have always done. Participants' reactions to men's involvement suggest a belief that it is not in 
men's nature to do good as it apparently is for women. The question of how doing good occurs, examined in this section, is of course linked to the question of who does good and, for many participants, even connected to who is good.

\section{Being Good}

Many of the activists and volunteers I encountered seemed to operate from the belief that those who do good are good. A potential consequence of this belief is that if only particularly gendered, raced, or classed individuals are constructed as the do-gooders, then only particular individuals will be constructed as good people. In other words, the presumption that doing good equals being good has consequences for whole groups based on social categories. An individual's social location impacts the particular opportunities and obstacles that enable or impede her ability to participate in efforts to do good. It is therefore relevant to consider the extent to which activists hierarchically categorize their acts of compassion.

Their work in the breast cancer or campus antirape movement is just one of a number of ways that participants express their personal philosophies of being good. Several participants at Stop Rape told me that they do advocacy because they intend to eventually pursue helping professions. Over the course of my participation at Stop Rape I learned that Teresa wishes to be an attorney so that she can provide legal advocacy throughout her life, Lynn intends to work for a nongovernmental organization, Olivia wants to be a rape counselor, and Kate hopes to work in medical services. All of these women envision a personal and professional life ahead of them filled with doing good. They have incorporated their commitment to doing good into all realms of their lives. Lynn also suggests that doing good is connected to a broader life philosophy about being good. When asked about what she finds rewarding about her participation, she said:

The reason that I got involved actively doing something is that it compliments my philosophies and ideology. I think that it would be very easy for myself, for anybody, to say, oh, you know, these are important issues and yes, I believe in these issues and these are important to me. And it's rewarding to go out and actually do something about them.

For Lynn, doing good means leading a fulfilling life that reflects her individual values and beliefs. Lynn also does good because it means gaining a sense of personal fulfillment. Though she didn't mention it, Lynn's opportunities for "actively doing something" are numerous and more easily 
accessible than if she were not a student because the college makes such opportunities available for students and known to students.

Like Lynn, the women at the Komen Foundation conceive of doing good as more broadly related to being good. Participants at both Komen and Stop Rape seem to operate with an ideal image of the good voluntary worker in their minds. But, as was Robert Bellah's observation about Americans who participate in voluntary activities, "They have difficulty relating this ideal image to the large-scale forces and institutions shaping their lives" (1985, 93). This ideal image also varies slightly for participants in different organizations. At Stop Rape, participants seem unaware of their privilege as college students and the ways that their social positions enable their participation. Participants at Komen, on the other hand, seemed unable or unwilling to explicitly draw connections between their efforts and the social organization of breast cancer, a disease that overwhelmingly affects women and is deadlier for African Americans, lesbians, and women of lower socioeconomic status (American Cancer Society 2006; National Breast Cancer Coalition 2006).

Instead of explicitly confronting the inequalities that breast cancer is centered around, Komen operates from the perspective that social change is best achieved when it is "positive and proactive," as a Komen participant once explained it to me. A positive approach implies not complaining; a proactive one emphasizes the importance of doing something. From the Komen perspective, it is important to do something but to do it without complaining. Not only do they avoid complaining about the social organization of breast cancer, this philosophy carries through to the day to day interactions at Komen. As I waited for one race planning meeting to begin, Darla leaned over and told me, "I'm not really sure why we're having this meeting tonight, but I guess it's fine with me to be here, even if I'm not exactly sure why I'm here." Darla typifies Komen's approach: it is alright to ask questions in some circumstances, but questions should not appear to impinge on the smooth operation of the group, even when it is not clear how what one is being asked to do actually contributes to that smooth operation.

By "going along to get along," Darla represents the Komen women's ideal image of the do-gooder. This image also becomes apparent when confronted with someone who does not meet the ideal. For example, the way that participants connect doing good with being good can be seen in their remarks about a local controversial politician whose gruff, hyper-masculine stature and style often put him in the media spotlight and whose wife had been slated to chair an upcoming event. Known for his loud, somewhat rude, and obnoxious demeanor, this politician was a far cry from the Komen 
women's ideas about doing good, being good, and how best to accomplish these goals. At one steering committee meeting Jill's update on race planning included the following:

Jill's biggest piece of news was that after much convincing [the politician's wife] has agreed to be an honorary chairperson of the local Race for the Cure. Polly and Jane turned to each other and one of them asked the other whether she thought [the politician himself] would be there. I heard Jane say, "I don't want him there" in a disgusted tone and Polly replied with a smirk, "He'll probably wear one of his motorcycle t-shirts."

Doing good and being good are intimately connected. Even though having the support of this politician's family might have had positive repercussions for Komen, Jane and Polly were clear that they did not want anything to do with those positive repercussions if it meant having someone attend the Race wearing a motorcycle t-shirt. Furthermore, several steering committee members expressed resentment over the fact that getting the politician's wife to agree to chair the Race took "so much convincing." The Komen women did not view what they were asking as particularly burdensome. In fact, they expressed that politicians' wives should be chairing such events. Also, their antagonism seemed directed at both the politician and his wife. They viewed her as having a formal duty because of her role as a politician's wife and they feared that he might "crash" the event by wearing inappropriate attire. The Komen women's concern highlights class differences between them and the couple. Their reaction reveals how equating doing good with being good is linked to social location. It was not enough that the politician's wife had agreed to chair the event. She and her husband were also expected to come particularly attired. In addition, that Komen's interest in this case was on getting a politician's wife to chair the event, rather than a woman politician herself, tells us something about the prevalence of normative gender ideologies within Komen.

At Stop Rape, social location is also linked to the doing good/being good connection but in more subtle ways. Instead of discussions that are overtly classed or raced, it is particular silences that reveal these connections. Many Stop Rape advocates talk about their advocacy as being linked to a general philosophy of wanting to "make a difference" but they do not mention how their ability to do so is facilitated by their status as college students with more time and more resources than others their age who do not attend college. That this fact was never explicitly considered in any of my conversations with advocates is noteworthy because silences have the effect of marginalizing those not mentioned and of essentializing differences 
between those who do good and those for whom opportunities to do good are less accessible. As Higginbotham (1996) notes, there is indeed a "politics of silence" (p. 195).

As with the Stop Rape participants, those at Komen also seem generally unaware of how they might differ from others in terms of accessibility to particular ways of doing good. That they do all of their work for free is telling of their own social locations. At Komen, those who do good for free are sometimes constructed as more good. Stop Rape advocates also receive kudos for volunteering, especially because they are involved in lots of other activities at school. In both cases, some form of capital (time or money or both) is being given up by those who do good. At Komen, implicit in participants' descriptions of what they do, is the suggestion that the fact that they are not being paid is evidence that the good they are doing is genuine. While the majority of Komen participants are volunteers, some affiliate offices do pay individuals to complete certain tasks that are necessary to putting on the annual Race. One time Polly and Jane visited an office in another state and came back with the following story, which I describe in the following excerpt from my field notes:

The Mountain City director told them that she pays people to help with the Race for the Cure mailings. Jane and Polly pointed out to me that in our affiliate, we depend entirely upon volunteers. They seemed to express pride in this fact, and were a little chagrined that any affiliate would pay people to do work that "should" be done by volunteers.

Polly and Jane's description of the Mountain City approach implies that it is more good to do things for free. What they do not express, however, is that their social locations, as married women without paid jobs whose husbands occupy prestigious and well-paid positions, enable them to do things for free. As with earlier women social reformers (Evans 1997; McCarthy 1990), Jane and Polly occupy positions of power relative to many women and the way that they go about doing good reinforces existing social class boundaries.

In addition to ideal images of who does good, the doing good/being good connection conjures up ideal images of how to be good. Komen participants not only grapple with how to "be good" in their volunteer work, many also struggle with how to be good survivors. Their actions and their own descriptions of their efforts promote the perspective that being a good survivor is one way of doing good. Being a good survivor means setting a good example to other women with breast cancer and to others in general and it shows that breast cancer survivors know how to take care of themselves. 
Portions of the book by Komen founder Nancy Brinker provide what could be understood as a sort of recipe for being a good breast cancer survivor (Brinker and Harris 1995). At one point in the description of her own personal story, Brinker discusses the decision that many women with breast cancer face when confronted with the reality of losing their hair during chemotherapy. Brinker says her decision to wear a wig rather than exposing her bald head was “. . . a matter of preserving my dignity. I didn't want to give people any more reason to pity me. Letting myself go would have been, in my eyes, a form of surrendering to the disease. I was determined to stay on top of the situation as much as possible" (Brinker and Harris 1995, 39). That Brinker viewed exposing a bald head as evidence of letting herself go and of "surrendering to the disease" demonstrates the Komen philosophy that good breast cancer survivors are those who set an example by not allowing breast cancer to prevent them from maintaining their feminine characteristics. And Brinker's readers express that the model she provides is a good one. In an endorsement of the book, former First Lady Nancy Reagan said, "Having had breast cancer myself, I applaud Nancy Brinker's book for helping women to face and deal with this problem. I hope it is read by every woman, no matter what age, everywhere" (Brinker and Harris 1995, dust jacket endorsement).

As in the breast cancer movement, for Stop Rape advocates who have experienced sexual violence themselves, participating as an advocate is one way to be a good survivor. Stop Rape advocates who wish to do so offer testimonials about their own sexual violence experiences every year during Sexual Violence Awareness month in April. The testimonials not only serve a personal function for advocates who wish to express their feelings publicly but they also provide an example to silent survivors about the power of speaking out (a process that Taylor [1996] refers to as "truth-telling"). ${ }^{4}$ That Stop Rape solicits testimonials from survivors suggests a desire to show others that "good" survivors are people who feel empowered and confident enough to tell their stories to others. Again, though, the point is seldom raised that the college campus environment is conducive to such public displays of good survivorship - it offers a newspaper in which to publish survivors' stories, provides a locale conducive to public rallies and events, and supplies an easily accessible audience of other students.

\section{Doing Good, Being Good, and the Politics of Empowerment}

These groups' focus on personal stories and the individual empowerment that comes with telling such stories could be understood as more self-help 
oriented than activist (see Taylor 1996 and Taylor and Van Willigen 1996 for more on this distinction). The concept of empowerment is in fact linked to the kinds of tensions between individualism and compassion that I describe earlier in the article. Is empowerment anything more than self-care? Is it at all political, and does it lead to broader social change? Responses to these questions can be found in participants' descriptions of what they do and why they do it.

Stop Rape advocate Linda told me in an informal interview during a training retreat that she believes that "empowering victim/survivors" is a primary goal of Stop Rape and of the sexual violence awareness movement. But Linda also said that "awakening the social consciousness to the issues and deconstructing why these problems exist" are central to Stop Rape's mission. Like Linda, other advocates frequently allude to empowerment as essential but they are also quick to include a comment about the need to educate everyone about sexual violence and to consider why it occurs. For example, when I asked Lynn during an in-depth interview what she sees as the goals of Stop Rape she said:

Well, one is obviously empowering victim-survivors. But the goal that I really enjoy is the peer education part. You know, the education, the awareness, and the awakening the social consciousness to the issues. Also, kind of deconstructing why these problems exist.

While empowerment is important for Stop Rape advocates, it is just one piece of their work. The other piece for Stop Rape participants focuses not on individual women in need of empowering but on communities in need of a reconstructed vision of gender equality and violence.

Empowerment is more central for Komen. The Komen women's work is driven in large part by a desire to empower women to believe in themselves and their rights so that they will take the initiative to advocate for their own health and ensure that their doctors assist them in this endeavor. In the published version of her personal story, Nancy Brinker describes how she founded Komen in part to empower women (Brinker and Harris 1995). Brinker says that she and her sister Susan Komen were both appalled to learn during Susan's treatment for breast cancer about the poor treatment women with breast cancer received, including not being fully informed by doctors about their conditions or treatment options. At that time, the sisters agreed that they wanted to change the way that women with breast cancer were treated by their doctors. After Susan died, Brinker founded the Komen Foundation because she "wanted to fulfill the pledge [she and her sister] 
had made about the way women with breast cancer were treated" (Brinker and Harris 1995, 26). Even twenty years after Komen's founding, breast cancer volunteers still cite the goal of empowering women in a way that they were not as a motivating factor for involvement in the movement. One participant I spoke with at a Komen event told me she felt horribly misunderstood and mistreated by her doctors. She said that because of the way she was treated, since her diagnosis she has served as an advocate for two friends who were diagnosed with breast cancer.

In each of the above examples, the emphasis is on empowering the individual. Thinking about social change in terms of the individual is arguably the most pervasive, most readily available way in America of conceiving the possibilities for social change. Stop Rape and Komen are both concerned with empowering women to believe in themselves as individuals with certain rights and responsibilities. Both organizations spend a significant portion of their resources on educating and providing advocacy for individuals. The bulk of Stop Rape advocate time is dedicated to staffing a twenty-four-hour crisis line. A nontrivial segment of Komen resources go toward promoting self-breast exam and increasing individual familiarity with one's unique body and health needs. Serving the immediate needs of individuals detracts organization resources away from serving the larger community. Whether out of necessity or preference, focusing too much on the individual works to the detriment of both organization's larger goals of better treatment for women (in health care, in relationships to others, and in all domains of life). By focusing as much on individuals as they do, participants in both organizations have less opportunity to consider the ways that breast cancer and sexual violence are social problems.

Though much of their focus is at the individual level, neither organization entirely neglects larger-level concerns. Some participants do demonstrate an understanding that gender relations are organized in such a way that even "empowered" women are often disempowered simply as a result of their gender identities - even empowered women are subject to sexual violence and even empowered women face an unfriendly healthcare system when they are diagnosed with breast cancer. Komen's answer to this problem is to try to increase general awareness about breast cancer (though critics point out that this is a rather vague goal). At a Komen fundraiser, one participant whom I asked about how she got involved told me, "I thought I was a pretty confident, take-no-prisoners kind of lady. Then I got this horrible disease and didn't know anything about it. It made me feel helpless. I don't want anyone else to go through that. I want everyone to know the facts about breast cancer." Though Stop Rape tends to employ a similar strategy, they 
also understand that recovery from and prevention of women's continued exposure to sexual violence would be much more likely if we changed, in one advocate's words, "the culture of violence that we live in."

One way that Stop Rape works to change the culture of violence that we live in is by having advocates speak about sexual violence, and the culture of violence, at the annual freshman orientation. By speaking at students' very first University event, Stop Rape advocates attempt to have all students begin the college experience with knowledge about gender equality and about behaviors that are incongruent with gender equality (e.g., rape and sexual harassment). But the culture of violence is illusive. And it is difficult to elucidate. Pinpointing which aspects of "culture" sustain the social problems of sexual violence and breast cancer is difficult for sexual violence and breast cancer activists alike. At Stop Rape, while talk about the culture of violence is common, it tends to be followed by individual-level summaries of the problem or suggestions for individual-level changes.

In a Stop Rape training session, participant Shelly said, "I agree that men should respect women but I think first we need to get them to respect themselves." In the first half of her comment, that men should respect women, Shelly suggests that she agrees with Stop Rape's position that advocates must work to promote a new vision of gender relations, one that is informed by mutual respect and is therefore inconsistent with the culture of violence. In this portion of her statement Shelly seems to be treating men and women as social groups rather than as specific individuals and this, I believe, demonstrates awareness about gender relations as structural and not just personal. But the suggestion that "first we need to get them [men] to respect themselves," comes close to a sort of quasi-psychoanalytic rhetoric that actually promotes the culture of violence by reducing gender-related problems to a problem of individuals simply not loving themselves enough. By reducing gender relations to an individual-level problem, Shelly ends up shifting her focus away from the fact that sexual violence is a social problem. While she aptly summarizes at least one of the reasons for the culture of violence in her remark about the need for men as a group to respect women as a group, Shelly's suggestion that the solution lies in individual men's feelings about themselves de-emphasizes the culture of violence.

Shelly is not the only participant for whom there seems to be a disjuncture between awareness about the culture of violence and awareness of how to eradicate it. When asked if Stop Rape makes a difference, Olivia said yes, but she described the difference that Stop Rape makes in very individual terms: "Because I know when I was a freshman and I came to campus, you know, and you read in all those, the little pamphlets that they send you, 
like the safety things: 'don't walk alone in the dark,' and there's these blue phones if something happens with the blue lights, you can call. ..." In addition to these signals that the culture of violence is alive and well on campus, Stop Rape also displays posters around campus and advocates perform skits in dorms and in classrooms intended to demonstrate and promote healthy gender relations. But these things did not come up when Olivia considered why and how Stop Rape makes a difference. Instead of citing Stop Rape's efforts to change the culture of violence, Olivia recalled what she had learned from Stop Rape about how to behave within the existing culture of violence: Don't walk alone at night and use the blue phones if something bad happens to you. Despite intensive training, and often personal experience with some form of victimization that is directly attributable to the culture of violence, advocates find themselves so immersed in this culture that even they struggle to cite ways to change it.

Advocate rhetoric thus comes back to the individual; perhaps because advocates have grown up in a society that rewards individuals for taking care of their own problems rather than seeking blame or solutions in or from others. This tension is relevant for understanding how participants do good. It demonstrates that in spite of valiant efforts to construct sexual violence as a social problem, even participants in the movement against sexual violence struggle with remembering that the solution to social problems lies, at least in many respects, outside of the individual. That is, remembering that sexual violence is a social problem is a struggle because of the social, political, and cultural (American) context within which these participants operate.

Although Komen as an organization is among the least likely of all breast cancer movement organizations to emphasize the social conditions (including environmental degradation and inequalities of race, class, and sexuality) that have been linked to breast cancer (see King 2006), its participants nevertheless do contribute to increased public consciousness about breast cancer by sharing their personal stories of empowerment. In a prior publication (Blackstone 2004), I discuss Pamela's story in which she describes having been "brushed aside" by her doctor after she inquired about the possibility of a link between the environment and her own and other women's breast cancer. Even though Komen does not push the issue publicly, participants like Pamela and others do recognize that breast cancer and its cure are linked to forces larger than the individual women who are inflicted with the disease (see Blackstone 2004 for additional examples). Even Nancy Brinker's expressed motivations for starting the organization hint that she saw connections between the social structure of disease and treatment and individual women's experiences. 


\section{Discussion and Conclusion}

This comparison of activism in the breast cancer and antirape movements reveals how activists' acts of compassion are gendered. I have sought to bridge contributions from the civic engagement literature with those from work by social-movements scholars on the roles of gender and emotions in shaping movement participation. In sum, the cultural context of individualism operates together with the gendered character of social movements to shape the processes by which participants do their good works and construct themselves as moral beings. Moreover, the examples provided here show how an individual's social location shapes the opportunities she has and the obstacles she faces in her efforts to do good, but that participants tend to be unaware about how their own realities might differ from those of individuals not like themselves. What is clear in speaking with participants across both movements is that they make sense of their own efforts to do good in very personal ways. Participants express that they do good because it simply reflects their personal beliefs and philosophies. Sometimes they express that doing good should only be done in particular ways that reflect their own personal style or way of life. But while activists and volunteers make sense of their own participation from an arguably individualist perspective, they participate (at least in part) because they wish to "make a difference" in some way that goes beyond the individual. The seeming incompatibility between participants' individualist perspectives and their desire to change some aspect of the broader culture raises questions about the transformative potential of their acts of doing good.

Prior research suggests that it is not just the act of doing good that transforms individuals and societies but that it is also the descriptions people offer about their efforts to do good that are transformative. As Wuthnow (1991) suggested, volunteers' narratives about their efforts represent "a vitally important part of their caring" and these narratives reflect "their own individualism and the culture that created it" (p. 85). At Stop Rape and Komen, participants tell their own stories to other participants and to those throughout the community as they give public testimonials about their experiences with sexual violence or breast cancer. At the conferences I attended, participants offered narratives of their personal stories through lobbying and rallies. The sexual violence awareness advocates who walked cross country offered their narratives to people across the nation in their efforts to raise awareness about sexual violence. I suggest that it is the telling of these stories, as activists go about the work of doing good, which connects individuals to something beyond themselves. It is also in the telling of these stories 
that activists and volunteers reveal the ways that their participation is linked to their own social locations as gendered, classed, and raced beings at particular stages of life and within particular generations.

The extent to which participants' acts and stories of doing good are transformative is revealed in two central points highlighted in the analysis presented here. First, doing good is gendered. Evidence that doing good is gendered is provided by constructions of men participants as heroes and women participants as nurturers and by the fact that opportunities for participation are differentiated by gender. That participants sometimes equate doing good with being good must also be taken into account when considering the extent to which doing good is transformative. Connections between doing good and being good are revealed in part by the value some participants place on being positive and on being good role models. These connections are also revealed in some participants' apparent belief that good people are those who are appropriately mannered and appropriately groomed. In some ways, these perspectives impede the transformative potential of doing good. While norms of day to day interaction may dictate that the participants described here behave in a way that is positive and exemplary, doing so may prevent them from taking a more critical look at the social problems being addressed by the movements in which they are involved. Connections between doing good and being good are also revealed in the fact that who can do good is limited. If only particularly gendered, raced, or classed individuals are constructed as people who do good, then the risk is run that only those particular individuals will be constructed as good people. Because the primary focus in this article has been on how the processes of doing and being good are gendered, future research might pick up from here and explore in more depth the race and class dimensions of these processes.

Furthermore, limited constructions of being good impede the possibilities for bringing new members into these movements as the notion of being good is tied to the emotional work of a social movement's successful operation. As Polletta and Amenta (2001) point out, the emotions that "animate" a movement shape "its recruitment processes, the strategies it chooses, and the impacts it has" (p. 315). Thus an additional line of research that could build from this work might be centered on how movement participants' constructions of themselves as "good," moral beings contributes to and/or impedes its success in recruiting members and creating social change.

In the end, participants' acts and descriptions of doing good are potentially transformative but my data also reveal a class-based lack of awareness about gendered practices. Because of this lack of awareness, the participants' 
efforts to "do good" fall short in terms of their transformative potential. This fact does not imply, however, that participants' acts of doing good lack all transformative potential. For example, by speaking publicly about personal experiences with sexual violence or breast cancer activists and volunteers challenge ideals of women as quiet and nonconfrontational. At the same time, a group of young men walking across the nation to share stories about sexual violence in at least some ways reproduces the ideal image of males as rugged individualists. Though this and other examples show that participants sometimes reproduce ideas about and ideals centered around gender, they simultaneously challenge those ideals. Perhaps without realizing it, by providing an opportunity for Men for the Cure to work collectively in creating a garden in honor of breast cancer survivors, the Komen women offer up new images of men's participation, alternative to the prototypical individualist image. It is these and similar efforts that reveal the promise, or at the very least potential, of transformation.

\section{Notes}

1. I should note that the bulk of my data on the breast cancer movement come from an organization whose approach represents just one of several dominant perspectives in the breast cancer movement (see, e.g., Fosket 2000; King 2006; Klawiter 1999; Potts 2000; Simpson 2000). The extent to which breast cancer movement organizations emphasize cause, cure, or treatment varies greatly. My focus is on only one strain within the movement - that which primarily emphasizes cure and issues related to treatment such as detection, care, and the process of surviving cancer.

2. Having conducted this ethnography over a period of several years means that I was able to collect enough data that some portions of it go beyond my original focus on gender. In the analytic sections of the article I therefore share a few results that speak to the class and race dimensions of doing good. These portions of the analysis are not as well developed as those centered around gender but I include them in the article with the hope that they may provide a useful starting place for future research aimed at examining how participants construct compassion as a classed and raced phenomenon.

3. Komen's stated mission is, "To eradicate breast cancer as a life-threatening disease by advancing research, education, screening, and treatment." Stop Rape's mission is to identify, reduce, eliminate, and eradiate sexual violence and other forms of oppression in the community.

4. Of course, the power of speaking out must be tempered with the knowledge that individual stories should not be understood as representative of all women's experiences or as something that alone can solve the social problems of sexual violence or breast cancer.

\section{References}

Adams, J. 2002. Gender and social movement decline: Shantytown women and the prodemocracy movement in Pinochet's Chile. Journal of Contemporary Ethnography 31 (3): 285-322. 
American Cancer Society. 2006. Breast cancer facts \& figures: 2005-2006. Atlanta: American Cancer Society, Inc.

Beisel, N. 1997. Imperiled innocents: Anthony Comstock and family reproduction in Victorian America. Princeton, NJ: Princeton University Press.

Bellah, R. N. 1985. Are Americans still citizens? The Tocqueville Review 7: 89-96.

Bellah, R. N., R. Madsen, W. M. Sullivan, A. Swidler, and S. M. Tipton. 1985. Habits of the heart: Individualism and commitment in American life. Berkeley: University of California Press.

- 1991. The good society. New York: Alfred A. Knopf, Inc.

Berlin, I. 1984. Two concepts of liberty. In Liberalism and its critics, edited by M. Sandel, 15-36. New York: NYU Press.

Bevacqua, M. 2000. Rape on the public agenda: Feminism and the politics of sexual assault. Boston: Northeastern University Press.

Blackstone, A. 2003. Racing for the cure and taking back the night: Constructing gender, politics, and public participation in women's activist/volunteer work. $\mathrm{PhD}$ dissertation, Department of Sociology, University of Minnesota, Minneapolis.

- 2004. "It's just about being fair": Activism and the politics of volunteering in the breast cancer movement. Gender \& Society 18 (3): 350-68.

- 2007. Finding politics in the silly and the sacred: Antirape activism on campus. Sociological Spectrum 27 (2): 151-63.

Brinker, N. G., and C. M. Harris. 1995. The race is run one step at a time: My personal story. Arlington, TX: The Summit Publishing Group.

Brownmiller, S. 1975. Against our will: Men, women, and rape. New York: Ballantine Books.

Burawoy, M. 1998. The extended case method. Sociological Theory 16 (1): 4-33.

Calnan, M., and S. Cant. 1990. The social organisation of food consumption: A comparison of middle and working class households. The International Journal of Sociology and Social Policy 10 (2): 53-9.

Charmaz, K. 2005. Grounded theory in the 21st century: Applications for advancing social justice studies. In The Sage handbook of qualitative research, 3rd edition, edited by N. K. Denzin and Y. S. Lincoln. Thousand Oaks, CA: Sage.

Clemens, E. S. 1997. The people's lobby: Organizational innovation and the rise of interest group politics in the United States, 1890-1925. Chicago: University of Chicago Press.

Coontz, S. 1992. The way we never were: American families and the nostalgia trap. New York: Basic Books.

Daniels, A. K. 1985. Good times and good works: The place of sociability in the work of women volunteers. Social Problems 32 (4): 363-74.

-1988. Invisible careers: Women civic leaders from the volunteer world. Chicago: The University of Chicago Press.

della Porta, D., and M. Diani. 1999. Social movements: An introduction. Oxford: Blackwell.

DeVault, M. L. 1991. Feeding the family: The social organization of caring as gendered work. Chicago: University of Chicago Press.

Evans, S. 1997. Born for liberty: A history of women in America. New York: Free Press Paperbacks.

Faludi, S. 1991. Backlash: The undeclared war against American women. New York: Doubleday.

Ferree, M. M., and P. Y. Martin, eds. 1995. Feminist organizations: Harvest of the new women's movement. Philadelphia: Temple University Press.

Flam, H., and D. King, eds. 2005. Emotions and social movements. New York: Routledge. 
Fosket, J. 2000. Problematizing biomedicine: Women's constructions of breast cancer knowledge. In Ideologies of breast cancer: Feminist perspectives, edited by L. K. Potts, 15-36. New York: St. Martin's Press.

Gerson, K. 2002. Moral dilemmas, moral strategies, and the transformation of gender: Lessons from two generations of work and family change. Gender \& Society 16 (1): 8-28.

Gerstel, N. 2000. The third shift: Gender and care work outside the home. Qualitative Sociology 23 (4): 467-83.

Giddens, A. 1979. Central problems in social theory: Action, structure, and contradiction in social analysis. Berkley: University of California Press.

Ginsburg, F. 1989. Contested lives: The abortion debate in an American community. Berkeley: University of California Press.

Glaser, B. G., and A. L. Strauss. 1967. The discovery of grounded theory: Strategies for qualitative research. Chicago: Aldine Transaction.

Goodwin, J., J. M. Jasper, and F. Polletta, eds. 2001. Passionate politics: Emotions and social movements. Chicago: University of Chicago Press.

Hays, S. 1996. The cultural contradictions of motherhood. New Haven, CT: Yale University Press.

Higginbotham, E. B. 1996. African-American women's history and the metalanguage of race. In Feminism \& history, edited by J. W. Scott, 183-208. New York: Oxford University Press.

Jasper, J. M. 1998. The emotions of protest: Affective and reactive emotions in and around social movements. Sociological Forum 13 (3): 397-424.

King, S. 2006. Pink ribbons, inc.: Breast cancer and the politics of philanthropy. Minneapolis: University of Minnesota Press.

Klawiter, M. 1999. Racing for the cure, walking women, and toxic touring: Mapping cultures of action within the bay area terrain of breast cancer. Social Problems 46 (1): 104-26.

Lichterman, P. 1996. The search for political community: American activists reinventing commitment. New York: Cambridge University Press.

Lofland, J., and L. H. Lofland. 1995. Analyzing social settings: A guide to qualitative observation and analysis. Belmont, CA: Wadsworth.

Lorber, J. 1997. Gender and the social construction of illness. Thousand Oaks, CA: Sage.

MacIntyre, A. 1984. The virtues, the unity of a human life and the concept of a tradition. In Liberalism and its critics, edited by M. Sandel, 125-48. New York: NYU Press.

McAdam, D. 1992. Gender as a mediator of the activist experience: The case of Freedom Summer. American Journal of Sociology 97 (5): 1211-40.

McCarthy, K. D., ed. 1990. Lady bountiful revisited: Women, philanthropy, and power. Brunswick, NJ: Rutgers University Press.

Mink, G. 1990. The lady and the tramp: Gender, race and the origins of the American welfare state. In Women, the state, and welfare, edited by L. Gordon, 92-119. Madison: University of Wisconsin Press.

Naples, N. A. 1992. Activist mothering: Cross generational continuity in the community work of women from low-income urban neighborhoods. Gender \& Society 6 (3): 441-63.

1998. Grassroots warriors: Activist mothering, community work, and the war on poverty. New York: Routledge.

National Breast Cancer Coalition. 2006. Facts about breast cancer in the United States: Year 2006. Washington, D.C.: National Breast Cancer Coalition.

Odem, M. E., and J. Clay-Warner, eds. 1998. Confronting rape and sexual assault. Wilmington, DE: Scholarly Resources Inc.

One in Four. (n.d.). http://www.oneinfour.com. Accessed May 2002. 
Pardo, M. 1995. Doing it for the kids: Mexican American community activists, border feminists? In Feminist organizations: Harvest of the new women's movement, edited by M. M. Ferree and P. Y. Martin, 356-71. Philadelphia: Temple University Press.

Petrzelka, P., and S. E. Mannon. 2006. Keepin' this little town going: Gender and volunteerism in rural America. Gender \& Society 20 (2): 236-58.

Polletta, F., and E. Amenta. 2001. Conclusion: Second that emotion? Lessons from once novel concepts in social movement research. In Passionate politics: Emotions and social movements, edited by J. Goodwin, J. M. Jasper, and F. Pollettta, 303-16. Chicago: University of Chicago Press.

Potts, L. K. 2000. Introduction: Why ideologies of breast cancer? Why feminist perspectives? In Ideologies of breast cancer: Feminist perspectives, edited by L. K. Potts, 1-11. New York: St. Martin's Press.

Ragin, C. C. 1987. The comparative method: Moving beyond qualitative and quantitative strategies. Berkeley: University of California Press.

Rawls, J. 1984. The right and the good contrasted. In Liberalism and its critics, edited by M. Sandel, 37-59. New York: NYU Press.

Ray, R. 1999. Fields of protest: Women's movements in India. Minneapolis: University of Minnesota Press.

Reagan, L. J. 1997. When abortion was a crime: Women, medicine, and law in the United States, 1867-1973. Berkley: University of California Press.

Ryan, M. P. 1992. Gender and public access: Women's politics in nineteenth-century America. In Habermas and the public sphere, edited by C. Calhoun, 259-88. Cambridge, MA: MIT Press.

Simpson, C. 2000. Controversies in breast cancer prevention: The discourse of risk. In Ideologies of breast cancer: Feminist perspectives, edited by L. K. Potts, 131-52. New York: St. Martin's Press.

Taylor, V. 1996. Rock-a-by baby: Feminism, self-help, and post-partum depression. New York: Routledge.

Taylor, V., and M. VanWilligen. 1996. Women's self-help and the reconstruction of gender: The postpartum support and breast cancer movements. Mobilization: An international journal 1 (2): 123-42.

Taylor, V., and N. Whittier. 1992. Collective identity in social movement communities: Lesbian feminist mobilization. In Frontiers in social movement theory, edited by A. D. Morris and C. M. Mueller, 104-29. New Haven: Yale University Press.

Thomas, J. 1993. Doing critical ethnography. Newbury Park, CA: Sage.

Tocqueville, A. 1966 [1835]. Democracy in America, edited by J. P. Mayer and M. Lerner. New York: Harper and Row.

West, C., and D. H. Zimmerman. 1987. Doing gender. Gender \& Society 1 (2): 125-51.

Wuthnow, R. 1991. Acts of compassion: Caring for others and helping ourselves. Princeton, NJ: Princeton University Press.

Amy Blackstone is an assistant professor of sociology at the University of Maine. In addition to her research on the breast cancer and antirape movements, she studies the sexual harassment experiences young workers including their perceptions of and responses to their experiences. 